\title{
LA RENDICIÓN DE CUENTAS A LA CIUDADANÍA POR LAS ENTIDADES NACIONALES*
}

\author{
ACCOUNTABILITY TO THE \\ CITIZENRY BY NATIONAL INSTITUTIONS
}

A RENDIÇÃO DE CONTAS À CIDADANIA DAS ENTIDADES NACIONAIS

\author{
Mario Alberto Álvarez López ${ }^{a}$ \\ marioalbertoal@gmail.com \\ Mercedez Restrepo Arias ${ }^{b}$ \\ restrepoariasmercedes@gmail.com \\ Recibido: 31-08-2012. \\ Aceptado: 25-09-2012
}

\section{RESUMEN}

El presente artículo corresponde al producto no. 3 del proyecto: "Formulación, reformulación e implementación de las políticas de competencia de los temas "empleo público", promoción y efectos del control social, y rendición de cuentas a la ciudadania" de la ESAP, y es una reflexión acerca de los cambios que se han generado en

\footnotetext{
*Artículo asociado a investigación realizada por los grupos de Gestión del Desarrollo y Educación del Desarrollo adscritos y reconocidos por Colciencias, en licitación de la Escuela de Administración Pública (ESAP) y el Departamento Administrativo de la Función Pública (DAFP), sobre las Acciones de promoción del Control Social realizadas por las entidades de la Administración Pública Nacional y territorial, los Organismos de Control y las Organizaciones no Gubernamentales, en las principales ciudades del país: Bogotá, Barranquilla, Medellín y Cali.

a. Economista de la Universidad La Gran Colombia, Especialista en Gestión y Planificación del Desarrollo Urbano y Regional de la Escuela Superior de Administración Pública, Especialista en Docencia Universitaria U.G.C., Magíster en Educación de la Universidad Católica de Manizales, Doctor en Educación Social de la Universidad de Granada España, Doctor en Ciencias de la Educación de la Universidad Tecnológica de Pereira. Par Académico de Colciencias, Líder del Grupo de Investigación Gestión del Desarrollo. Autor de los libros (Significación del Desarrollo 20o8), (Modelo de Desarrollo 2008), (Aproximación al Concepto 2008), entre otros y articulista.

b. Economista, especialista en Administración pública, en Docencia y pedagogía universitaria, Magíster en Educación y estudiante de doctorado en Economía Política de la Universidad de la Habana. Integrante de los grupos de investigación Gestión del desarrollo y de INNOVATic.
} 
los procesos de rendición de cuentas a la ciudadanía, por parte de la administración pública en entidades del orden nacional, a través de la construcción de la matriz DOFA sobre rendición de cuentas, como resultado de la información capturada en las entidades públicas del orden nacional. Para ello, se parte de la siguiente pregunta: ¿qué ha cambiado en los procesos de rendición de cuentas a la ciudadanía en la vigencia 2009-2010? De lo cual se concluye que los cambios generados con el proceso de rendición de cuentas a la ciudadanía, por parte de la administración pública de las entidades del orden nacional, han sido positivos con respecto al cumplimiento de la normatividad, pero aún es necesario superar una serie de debilidades y amenazas que presenta el proceso como lo son: la falta de inclusión y la poca apertura por parte de los funcionarios, para hacer pública la información.

\title{
PALABRAS CLAVE
}

Rendición de cuentas, participación ciudadana, control social del ciudadano, entidades de la administración pública.

\begin{abstract}
This article is a reflection of the changes that have been generated in the process of accountability to citizenry by public administration in national entities, through the construction of the SWOT matrix on accountability as a result of the information captured in the national public entities. To this end, it was taken this question as a starting point: what has changed in the process of accountability to citizenry in the period 20092010? It was concluded that the changes generated with the process of accountability to citizenry, by the national government entities, have been positive regarding to the compliance with regulations, but still need to overcome a number of weaknesses and threats that this process present such as: the lack of inclusion and the lack of openness on the part of officers to make the information public.
\end{abstract}

\section{KEY WORDS}

Accountability, citizen participation, social control of the citizen, public administration entities.

\section{RESUMO}

O presente artigo corresponde ao produto No. 3 do Projeto "Formulación, reformulación e implementación de las políticas de competencia de los temas "empleo público", promoción y efectos del control social y rendición de cuentas a la ciudadanía" da ESAP, e, é uma reflexão com respeito das mudanças que tem se gerado nos processos de rendição de contas à cidadania, por parte da administração pública em entidades da ordem nacional, através da construção da matriz DOFA sobre rendição de contas, como resultado da informação obtida nas entidades públicas da ordem nacional. Para isso, se inicia a partir da seguinte pergunta: ¿o que tem mudado nos processos de rendição de contas à cidadania na vigência 2009-2010? Do que se conclui que as mudanças geradas com o processo de rendição de contas à cidadania por parte da administração pública das entidades da ordem nacional, tem sido positivas a respeito 
do cumprimento da normatividade, mais ainda é preciso superar uma série de debilidades e ameaças que apresenta o processo como são: falta de inclusão e pouca abertura por parte dos funcionários para fazer pública a informação.

\section{PALAVRAS-CHAVE}

Rendição de contas, participação cidadã, controle social do cidadão, entidades da Administração Pública.

\section{INTRODUCCIÓN}

La rendición de cuentas a la ciudadanía por parte de las entidades nacionales, tiene como principal objetivo la construcción de la matriz DOFA sobre RC, como resultado de la información capturada en las entidades públicas del orden nacional, funcionarios y ciudadanía. Se describe la problematización de la investigación en los términos de formulación y sistematización de los interrogantes que orientan el objeto de estudio. Se acompaña de un constructo hipotético que permite al final de la investigación contrastar las afirmaciones realizadas con los resultados obtenidos, en función de alcanzar los objetivos propuestos y el producto de análisis de la matriz DOFA. Se consignan los referentes legales y conceptuales, sobre los cuales descansa el desarrollo de la investigación, pasando desde la arquitectura normativa del tema de la rendición de cuentas, hasta alcanzar la carga de significación que adquieren algunos términos de común uso en el desarrollo de la investigación. Se hace referencia a los aspectos metodológicos que sustentan las técnicas e instrumentos para recolectar, procesar y categorizar la información, partiendo de la unidad de análisis, que es el documento aportado por las entidades de la administración pública de orden nacional y territorial seleccionado, lo mismo que la información aportada por la comunidad y los funcionarios públicos.

Finalmente, se presenta el componente analítico desde el punto de vista estadístico, resultado de talleres focales y análisis documental que llevó a la construcción de la DOFA en la etapa de diagnóstico, vulnerabilidad y enunciado final.

\section{PROBLEMA DE INVESTIGACIÓN}

¿Cuáles han sido los cambios generados con el proceso de rendición de cuentas a la ciudadanía por parte de la administración pública de las entidades del orden nacional?

\section{METODOLOGÍA}

El diseño metodológico es semi-cuantitativo y de tipo empírico-analítico; el enfoque epistemológico es funcional-estructuralista, por lo cual requirió del análisis de los cambios que se han generado en los procesos de RC a la ciudadanía por parte de la administración pública en entidades del orden nacional. En la investigación se utiliza la técnica DOFA, para hacer el análisis de vulnerabilidad que permite determinar los cambios que se han generado en los procesos de rendición de cuentas a la ciudadanía, por parte de la administración pública en entidades del orden nacional, ante las inadecuadas prácticas de RC a la ciudadanía. 
La población total de los ciudadanos susceptibles de ser consultados son los que forman parte de las bases de datos institucionales de las entidades de la administración pública, objeto de valoración en el presente estudio. De estas, se invitaron para participar en los talleres a ciudadanos inscritos en las bases de datos de la Red de Apoyo a las Veedurías Ciudadanas, pertenecientes a organizaciones sociales y Organizaciones No Gubernamentales (ONGS), cuyo objetivo fue la valoración de dicho proceso de RC.

Para el análisis documental se diseñó un instrumento que permitió identificar y valorar las evidencias (disposición de la información, espacios de interlocución, sanciones e incentivos y otros de interés para la investigación) a partir de categorías relacionadas con dicho proceso, sobre la cualificación del proceso de rendición de cuentas por parte de las entidades nacionales, en los años 2009 y 2010, un protocolo y una guía taller para el grupo focal.

\section{RESULTADOS:}

\section{LA RENDICION DE CUENTAS}

Hay varias formas de entender la RC a la ciudadanía. Para la mayoría de las personas es una obligación del gobierno informar lo que ha hecho con los recursos públicos, y sobre las responsabilidades que le fueron asignadas; por ello, las entidades públicas presentan informes en una reunión pública a la ciudadanía. La rendición de cuentas que realiza el Estado debe ser entendida también como un deber y un derecho ciudadanos. Es una obligación del ciudadano exigir el informe de lo que ha hecho el gobierno, y el informe de cómo el gobernante ha utilizado el dinero que se le ha confiado para atender las necesidades sociales; es decir, realizar acciones de control social para asegurar el cumplimiento de los fines del Estado.

Teniendo en cuenta este antecedente y partiendo de los cambios generados con el proceso de rendición de cuentas a la ciudadanía, por parte de la administración pública de las entidades del orden nacional, que han sido positivos con respecto al cumplimiento de la normatividad, aún es necesario superar una serie de debilidades y amenazas, y aprovechar las fortalezas y oportunidades que ofrece la relación: administración pública, RC y control social del ciudadano.

Conocimiento y Actitud del ciudadano frente a la Participación en los procesos de Rendición de Cuentas. De acuerdo al conocimiento y actitud del ciudadano, sobre mecanismos, escenarios y acciones de promoción del control social, los ciudadanos manifestaron que con dicha finalidad, caben en $49 \%$ todos los ítems sobre los cuales fueron consultados. Si se analiza de manera desagregada la participación en los procesos de RC, apenas alcanzó el 12\% en cuanto a dicho conocimiento; lo que podría suponer que la opinión ciudadana, con respecto a esta acción del control social, es débil y, por tanto, debe tenerse en cuenta este aspecto en los procesos de capacitación, talleres focales y demás actividades que cualifiquen la capacidad ciudadana en torno a la importancia de la RC.

Conocimiento y Actitud del ciudadano frente a los procesos que se deben fortalecer en las entidades públicas. La opinión ciudadana manifiesta en el mayor porcentaje (23\%), que las entidades de la administración pública deben presentar con mayor calidad el proceso de rendición de cuentas. De este resultado se infiere que los procesos se deben cualificar en términos de información pertinente, oportuna, veraz y correspondiente a la gestión que cada entidad pública realiza. Además, dicho proceso no debe circunscribirse sólo a informes 
de gestión, sino que atienda a las demandas ciudadanas sobre la actividad desplegada por las entidades públicas, que tienen la obligación de rendir cuentas las veces que se les exija.

Motivación y expectativas para promover acciones del control social. Los aspectos que han fortalecido la participación ciudadana son los consejos ciudadanos, con sesenta y ocho (68) puntos, seguidos de las veedurias ciudadanas con cincuenta y ocho (58) y, posteriormente, aparecen otros aspectos, entre ellos, la rendición de cuentas con cuarenta y un (41) puntos. Este último dato es interesante, posiblemente muestra la exigencia cada vez mayor de RC por parte de la ciudadania, si se consideran los fenómenos de corrupción, de contratación y otros de índole político, significativos para la ciudadanía en el último periodo de gobierno. En cuanto a la motivación y expectativa expresada por el ciudadano, se evidencian las veedurías ciudadanas con cuarenta y cinco (45) puntos, los consejos ciudadanos con cuarenta y dos (42) y la RC con cuarenta y dos (42) puntos, que son aspectos que concitan las opiniones ciudadanas. Este factor es importante, posiblemente por el auge de las mismas veedurias ciudadanas que llevan implícita la exigencia a los procesos de RC.

\section{EXPERIENCIAS DE LAS ENTIDADES NACIONALES EN LA RENDICIÓN DE CUENTAS A LA CIUDADANÍA}

Tema de la Rendición de Cuentas para el periodo 2009-2010. Las entidades de la administración pública, seleccionadas en el estudio sobre la promoción del control social como: Ministerios de Educación, Hacienda y Crédito Público, Defensa Nacional, Protección Social, Minas y Energía; Superintendencias de Servicios Públicos Domiciliarios, de Sociedades, de Industria y Comercio, la Corporación Autónoma Regional de Rio-negro -NARE CORNAREcon el tema: gestión y seguimiento al PAT; alcaldías de Bucaramanga, Pasto, Cali, Villavicencio, Neiva, Tunja, Sincelejo, y gobernaciones de Huila, Boyacá, Meta, Valle del Cauca, Santander, Risaralda, Sucre, Nariño, entre otras, realizaron RC circunscritas a los informes de gestión, la Defensoría del Pueblo con el tema de los derechos humanos, el Instituto Colombiano de Bienestar Familiar con el análisis crítico de la situación de los niños, niñas y los adolescentes, aplicando el enfoque de derechos y poblacional; y la alcaldía de Pereira con el tema construcción de la red municipal de veedurías.

Dichas entidades en el informe de gestión para la RC consideraron los mínimos institucionales obligatorios como las metas del plan de desarrollo bajo su responsabilidad, y las acciones para el fortalecimiento institucional. En lo que tiene que ver con los temas de interés ciudadano, exteriorizaron la voluntad de atender quejas, peticiones, reclamos, sugerencias, y propuestas para atender el servicio o proceso de la entidad, derechos, problemas y servicios institucionales.

Se infiere del proceso de RC en cuanto a los informes de gestión ( $90 \%$ del total), que se les presentan a las comunidades, ONGS, y demás asistentes, información que en la mayoría de las veces obedece a la discrecionalidad de quienes presentan los informes de las entidades de la administración pública, es decir, estadísticas, cifras y datos generales de la gestión realizada que en ocasiones no incluyen información relevante para que la ciudadanía se entere, por ejemplo, de anomalías de procesos como las contrataciones, y como tal esto no permite una verdadera participación ciudadana en procesos tan importantes como los que significan la RC a la ciudadanía. 
En este contexto, se está de acuerdo con la tesis de Transparencia por Colombia en el informe anual del 2009, al argumentar que:

"El derecho de acceso a la información pública en Colombia presenta varias dificultades, entre las que se destacan las siguientes: entrega discriminada de la información pública, dependiendo de la cercania, argumentos, relevancia de solicitante y posibles efectos resultantes de la entrega; primacía de la excepción, sobre la norma; restricción a las solicitudes no acompañadas de soporte legal; información pública inexistente, deficiente y de difícil acceso, escasa publicidad de la misma; baja demanda de la ciudadanía y desconocimiento de sus derechos, de los mecanismos de control, de las instancias de participación y de las obligaciones y funciones de los funcionarios públicos; utilización de la información pública como un "bien privado" y su restricción como un mecanismo de intimidación". '. Adicionalmente, estos análisis "corroboran algunas de estas falencias y llaman la atención sobre la opacidad en el manejo de la información de un grupo importante de entidades públicas nacionales. Con un promedio de 66.4\%, los resultados muestran un panorama desprovisto de procesos claros de apertura informativa dirigida al ciudadano y evidencian las debilidades de las entidades a la hora de "bacer público lo que es público", 2

Sectores de la Administración Pública de la Rendición de Cuentas. Se priorizaron los siguientes sectores para el análisis: Alcaldías y gobernaciones con dieciséis (16) documentos de RC concernientes a los recursos financieros; el de los servicios públicos domiciliarios con dos (2); el de protección social, con uno (1); el de educación, con dos (2); el sector energético, con uno (1); el ambiental, con uno (1), y el de la defensa nacional con dos (2), por ser los más relevantes para las organizaciones sociales, veedurías ciudadanas y comunidad en general. Se destaca el sector de los recursos financieros, ya que es una de las principales preocupaciones de la sociedad civil y otros actores comunales, por cuanto tienen relación directa con la transparencia en la ejecución de los gastos y presupuestos de gobiernos municipales y departamentales. La inexactitud y el restringido acceso a la información pública sobre la ejecución de dichos gastos y presupuestos, alientan sombras y sospechas sobre la moralidad de los funcionarios públicos. En ese sentido, se ha avanzado en el país, donde las entidades públicas acuden a los medios de comunicación, radio y televisión institucionales, y a los medios electrónicos de acceso al público para entregar información sobre la ejecución de gastos y presupuestos.

Número de Rendiciones realizadas. La periodicidad para la RC de las entidades públicas del orden nacional, generalmente es de un año. Sin embargo, el documento CONPES 3564 considera dentro de los mecanismos definidos para la RC que su realización debe garantizarse en cualquier momento, como un proceso permanente entre las entidades públicas y los ciudadanos, dejando la idea de hacer una audiencia pública anual para informar únicamente sobre la gestión, y no interactuar con los diferentes actores de la sociedad civil. Por ello, dependiendo del requerimiento de cualquiera de los actores, las entidades públicas están en la obligación de preparar, filtrar o direccionar la información que se demande, no sin antes establecer la necesidad real de los ciudadanos y de las organizaciones sociales que la demanden. Se destaca la defensoría del pueblo con nueve (9) procesos de RC a la ciudadanía, lo que es lógico, dada las situación de demandas ciudadanas con aspectos relacionados en cuanto a los derechos humanos, procesos de desplazamientos, desapariciones, etc. De igual manera, se resaltan las alcaldías de Pereira con cinco (5) rendiciones, al parecer debido a la gestión de la

1. Transparencia por Colombia, Informe anual 2009. El acceso a la información pública en Colombia: ¿Un derecho vulnerado? Pág. 17 y 18 .

2. Óp. Cit. pág. 18 
actual administración municipal que ha mostrado gran interés en promocionar acciones del control social, evidenciadas por ejemplo en el impulso a la generación de nuevas veedurías ciudadanas, y la ciudad de Pasto con dos (2) RC. En cuanto a ministerios, se destacó el Ministerio De Defensa con cuatro (4) rendiciones, posiblemente por las urgencias que implica dar cuenta a la población de aspectos relacionados con modernizar equipamiento propio de las actividades de defensa, novedades en la estructura administrativa y contrataciones.

Población a la que se dirige la Rendición de Cuentas. Las entidades públicas objeto de estudio, dirigen la RC a la siguiente población: veintisiete (27) de ellas, a la ciudadanía en general, dieciocho (18) a las organizaciones sociales, dieciséis (16) a los mismos funcionarios de las entidades públicas, siete (7) de ellas, a las organizaciones no gubernamentales, y en menor proporción, cuatro (4) a los funcionarios de los organismos de control. Se observa que las entidades públicas del orden nacional dirigen en mayor proporción la $\mathrm{RC}$ a la ciudadanía en general, con respecto a los organismos de control, lo que posiblemente genera la creciente convicción de que es imposible un control efectivo de la corrupción sin una amplia participación de la sociedad civil organizada, así se esté avanzando en el desarrollo e implementación de mecanismos de control social de la gestión pública. Pues es evidente que la participación de las organizaciones sociales agrega un substancial nivel de control ante las fallas y deficiencias de los sistemas existentes, como los controles institucionales internos, las contralorías públicas, las supervisiones por las autoridades responsables, y el control de organismos legislativos.

\section{EVIDENCIAS DEL FUNCIONAMIENTO DE LA RENDICIÓN DE CUENTAS. PREPARACIÓN DE LA RENDICIÓN DE CUENTAS}

Alistamiento institucional. Las entidades públicas del orden nacional cumplen con la preparación de las audiencias públicas. El 76.6\% conforman un grupo de apoyo, que se encarga de preparar la información de forma sencilla, clara y concisa para el mejor entendimiento de la ciudadanía. Este grupo está presidido por la oficina de planeación de la entidad que va a hacer la rendición de cuentas, la cual se encarga del manejo de la información, y la conforma un representante de cada área de la entidad que respalda la consolidación de la información. El envío e intercambio de información entre las dependencias y las áreas de planeación (las últimas como coordinadoras de todo el proceso), permite obtener información precisa y simplificada. Conforman un equipo de relatoría integrado por uno o dos funcionarios de la entidad y uno por lo menos de la veeduría del proceso, para que recoja la encuesta de evaluación de los asistentes a la audiencia pública.

Identificación de interlocutores. Las entidades públicas cuentan con el 70\% de la base de datos con las organizaciones de la sociedad civil (asociaciones o comités de usuarios, consejos regionales, gremios, veedurías, universidades, medios de comunicación, asociaciones de profesionales, etc.), beneficiarias de sus servicios, y el $90 \%$ de las entidades públicas hacen registro de invitación de los usuarios a la rendición de cuentas para que actúen como interlocutores.

Divulgación y capacitación. En la mayoría de los casos las entidades divulgan la información, con 30 días de antelación a la fecha prevista para realizar la audiencia pública, para preparar a la ciudadanía sobre los alcances de la RC, como la mecánica del ejercicio, su alcance y sus límites. Acuden para ello, a espacios radiales con un $6 \%$, a espacios televisivos $23 \%$, boletín del consumidor y páginas web institucionales con el $30 \%$, y boletines de prensa $43 \%$, 
entre otros. En estos espacios se desarrollan programas de capacitación dirigidos a usuarios y/o a organizaciones de usuarios de sus servicios. Adicionalmente, el $40 \%$ de las entidades públicas no cumplen con la realización de encuentros preparatorios de la audiencia, entre la entidad y las organizaciones, de manera que permitan clarificar la información y propiciar el seguimiento a los procesos por parte de estas últimas. El 76\% de los funcionarios de las entidades públicas reciben capacitación, sensibilización e información sobre la estrategia de RC y sobre los mecanismos para su implementación.

Organización logística. La organización de las audiencias públicas de las entidades objeto de investigación, suplen las siguientes necesidades: El 100\% de ellas tienen previsto el lugar para la realización de la RC, se caracterizan por ser amplios, respondiendo a las necesidades de la entidad y de fácil acceso a la ciudadanía, y tienen en cuenta las normas básicas de seguridad. En cuanto a la fecha, el 100\% de las entidades la establecen para la realización de la RC, con 15 días de anticipación para que quienes deseen asistir reserven su agenda. Y el 86\% establecen el tiempo de duración. En cuanto a los suministros necesarios para la RC, el 83\% de las entidades públicas advierten sobre la cantidad de personas que se harán presentes en ésta, por lo que las proyectan antes para no tener que enfrentar contratiempos mayores, el día de la misma, por falta de logística y de recursos.

Reglamento de la audiencia de rendición de cuentas. En el reglamento de la audiencia las entidades públicas consideran: el 93\% una agenda para su desarrollo que tenga en cuenta aspectos varios, como tiempo y número de intervenciones, este tiempo es tenido en cuenta por el $73 \%$ de las entidades. El proceso de inscripción y radicación de propuestas es llevado a cabo por el $70 \%$ de las entidades, las cuales son recolectadas en un $73 \%$ por las mismas, en formato para la inscripción de propuestas. Es así como recogen varias inquietudes para luego retroalimentarlas, especifican las reglas de juego o acuerdos sobre el desarrollo de la sesión, de manera concertada con los comités de seguimiento. Finalmente, el 90\% de las entidades cuentan con el proceso de inscripción de asistentes y participantes que realizan preguntas en la $\mathrm{RC}$, así como el 70\% de las mismas cumplen con el análisis y clasificación de las propuestas y/o evaluaciones recibidas.

Utilización de medios para la divulgación de la convocatoria para la realización de la Rendición de Cuentas. Los medios de divulgación más utilizados por las entidades públicas del orden nacional son las páginas web institucionales y el Boletín del Consumidor, los cuales alcanzan el 100\% de utilización; le siguen, en orden de importancia, otros medios de divulgación, que ascienden al 50\%. Los boletines de prensa alcanzan el 43\% y, el 23\%, le corresponde al canal de televisión institucional, el 20\% para las audiencias públicas, el 17\% a la radio, el 13\% a las carteleras institucionales, el 10\% a los folletos, el $6 \%$ a las entrevistas televisivas o radiales, interlocución a través de Internet y mesas de trabajo, y, finalmente, el 3\% a consejos comunitarios. Entre 2009-2010 las entidades públicas del orden nacional invitaron a 15.221 personas, entre organizaciones de la sociedad civil identificadas como de amplia representación territorial, quienes hicieron sesenta y tres (63) intervenciones. Estas invitaciones las hacen con una copia del informe de RC (el cual en muchos casos lo entregan en medio magnético para abaratar costos); proponen un mínimo de organizaciones invitadas por la entidad. Otras organizaciones de la sociedad civil, no invitadas directamente, podrán ser participantes en la audiencia pública, con los mismos derechos de las invitadas. La ciudadanía es convocada a través de los medios masivos de comunicación. En la convocatoria se especifica que la información de la entidad esté disponible en su página web y en medio físico en los centros de documentación o de atención al usuario. 
Etapas de ejecución de la rendición de Cuentas. Son tres las etapas de ejecución de la RC: Contenidos, presentación de la RC de gestión y partes de la RC. Esta última contiene un ítem sobre intervenciones en general y aclaraciones del proceso de RC, que está relacionado con el diálogo crítico entre funcionarios públicos y asistentes: este es el centro vital de la RC. No se trata de la actuación de una de las partes (funcionarios públicos), sino de un ir y venir de preguntas y respuestas, de argumentos y contra-argumentos entre funcionarios públicos y asistentes a la audiencia pública. Cuando exigimos cuentas, se espera una información precisa y confiable. Cuando exigimos cuentas, con frecuencia, las justificaciones que recibimos deben ser convincentes. Por lo mismo, insistimos, en la interrogación, en el cuestionamiento y en la interpelación, La RC no es un derecho de petición. Es un derecho a la crítica y al diálogo. Partiendo de esta argumentación y teniendo en cuenta que la RC implica el derecho a recibir información sobre lo acontecido en las entidades públicas del orden nacional, y el compromiso oportuno de divulgar los datos necesarios para que los asistentes al acto de RC se pongan al corriente, ello implica también el derecho a recibir explicación y el deber de justificar el ejercicio que como funcionario público se posee.

Etapas de ejecución de la Rendición de Cuentas para el período 2009-2010. En cuanto al concepto contenido que implica la presentación de la RC financiera frente al presupuesto asignado, con una parte especial referente a la totalidad de la contratación, inclusive de personal, se observa que el $90 \%$ de las entidades públicas del orden nacional y territorial cumplen con esta etapa. No obstante, es de anotar que el proceso de RC se convierte en un informe general y hasta superficial de la gestión administrativa y de las entidades objeto de estudio, y, además, según se desprende de la matriz D.O.F.A. (ver matriz de impacto) hay que tener en cuenta la percepción manifestada por los funcionarios públicos y organizaciones sociales al manifestar que existe:

"Temor de los funcionarios públicos a mostrar los resultados y ejecución de los planes de desarrollo sectoriales y de entidades, dados los altos niveles de corrupción en la desviación de los dineros públicos" ${ }^{3}$.

Esta situación genera desconfianza en cuanto a los resultados obtenidos en lo que tiene que ver con los aspectos financieros de las entidades públicas, toda vez que las entidades cumplen con un gran porcentaje. No hay que olvidar que, en términos generales, la ciudadanía es renuente a participar en los procesos de RC, sobre todo los que tratan de la vigilancia y control de funcionarios públicos con responsabilidades administrativas, frente al manejo eficiente y transparente de los recursos.

En este orden de ideas, y con relación a la RC de gestión, los indicadores tienen un comportamiento muy análogo en cuanto a su cumplimiento. La explicación del objeto social de las entidades, la presentación de metas e indicadores de resultados y la presentación del plan para la presente vigencia, cumplen en un alto porcentaje (63\%, 90\% y $87 \%$ respectivamente). Por lo que se presume hipotéticamente que las organizaciones sociales y la ciudadana en general, cada vez son más cualificados dado que según resultados del análisis D.O.F.A. -Matriz de impacto: "Existen cartillas pedagógicas elaboradas por el D.A.F.P., por la Controlaría General de la República, y demás órganos de control, sobre los mecanismos de promoción del control social, dirigidas a las organizaciones sociales, veedurías ciudadanas, funcionarios públicos, organismos no gubernamentales y ciudadanía en general"4, para aumentar los procesos de capacitación en control social y política pública; lo que a su vez puede traer como motivación un mayor interés

\footnotetext{
3. DOFA. Matriz de impacto.

4. DOFA. Matriz de impacto.
} 
de la ciudadanía en conocer las diferentes fases previas a los procesos de RC y a participar de manera crítica en dichos eventos.

Dentro de la etapa de ejecución de la RC, y sus componentes que incluyen presentación del informe de RC por la entidad, y el plan y presupuesto para la siguiente vigencia, alcanza el 93\%, y la presentación de las evaluaciones o propuestas de acciones realizadas por organizaciones de la sociedad civil, previamente inscritas y con documentos radicados, representan el $70 \%$, y, por último, intervenciones en general y aclaraciones, al igual que en los componentes anteriores los resultados muestran un cumplimiento satisfactorio del $73 \%$ respectivamente. En este contexto, la participación de la ciudadanía en las fases previas al proceso de RC es destacada, toda vez que las organizaciones sociales se inscriben y a la vez envían documentación para participar en el proceso de RC, lo que en otras palabras, posiblemente se traduce en que hubo motivación a la ciudadanía con temas coyunturales que inciden en que los ciudadanos sientan la necesidad de participar en el proceso; esto además puede ser entendido porque se generó por parte de las entidades públicas y la ciudadanía, un proceso de concertación temática de manera directa, de tal forma que se consolidara el ejercicio del control social, la evaluación a la gestión pública, y el acercamiento entre las entidades públicas y los ciudadanos, dada la sensibilización sobre las temáticas a tratar.

Cumplimiento de lo establecido en la norma. Etapa de ejecución en cuanto al tipo de información. Se considera pertinente tener en cuenta los artículos 23 y 74 de la Carta Magna, la ley 962 de 2005 (anti-trámites) artículo 8, el artículo 5 (literales c y e), el artículo 91 (literal e) de la ley 136 de 1994, la ley 617 de 2000, artículo 79, expuestas en el marco normativo correspondiente a la RC y, siendo consecuentes con los aspectos normativos y demás reglamentación exigida a las entidades públicas en el proceso de $\mathrm{RC}$ a la ciudadanía, es imperativo acudir a lo preceptuado en los direccionamientos emanados desde la legislación en esta materia. En este contexto se tiene:

"La Rendición de Cuentas de la Administración Pública a la Ciudadanía es un mecanismo que está cobijado por la Ley 489 de 1998 y el Decreto 3622 de 2005, como instrumento se adopta dentro de las Politicas del Plan Institucional de Desarrollo Administrativo -Politica de Democratización de la Administración Pública, dirigida a consolidar la cultura de la participación social en la gestión pública, con el fin de facilitar la integración de los ciudadanos y servidores públicos en el logro de las metas económicas y sociales del país, y a construir organizaciones abiertas que permitan la rendición social de cuentas. La rendición de cuentas de la administración pública es un espacio de interlocución entre los servidores públicos y la ciudadaní; tiene como finalidad generar transparencia, condiciones de confianza entre gobernantes y ciudadanos, y garantizar el ejercicio del control social a la administración pública; sirviendo además de insumo para ajustar proyectos y planes de acción para su realización". 5

Teniendo en cuenta lo anterior, en la etapa de ejecución de la RC y el acápite cumplimiento de lo establecido en la norma, en la etapa de ejecución en cuanto al tipo de información, se puede desprender que la comprensión y la actualización alcanza el 100\%, lo oportuno el 93\%, lo disponible el $90 \%$ y lo completo el $80 \%$, respectivamente, lo que indica que la información en el proceso de $\mathrm{RC}$ presenta un alto nivel de éxito, lo que haría evidente que la información clara, concreta y precisa sobre la gestión de la administración pública, fortalece la participación ciudadana y contribuye a incrementar la calidad de las intervenciones de los organismos sociales; pues una información de calidad no solo se convierte en insumo para construir

5. www.dane.gov.co 
capacidad individual y colectiva en la demanda ciudadana por los resultados a la gestión pública, sino que al interior de las mismas instituciones públicas, éstas se "alimentan" de las opiniones y criterios de los ciudadanos, pues son ellos quienes en gran parte están definiendo criterios sustanciales para la estructuración de medios de comunicación que posibiliten comunicación en doble vía, a saber, ciudadanía con entidades públicas. Es de destacar además, que el acceso a la información pública es un derecho ganado por los ciudadanos y sus organizaciones sociales, y, como tal, corresponde al Estado obligatoriamente ofrecerla según lo estipulan las normas arriba referenciadas.

Cumplimiento de lo establecido en la norma. Etapa de ejecución en cuanto Diálogo y explicaciones. De igual manera, se evidencia que la composición del punto diálogo y explicaciones: comprensión en el lenguaje y exposición, y explicación de temas relevantes para los fines de las RC con el 97\%, así como procedimientos organizacionales claros y favorables al diálogo con 90\%, diálogos de doble vía con el 87\%, y convocatorias amplias y frecuentes con el 73\%, también arrojan un porcentaje muy significativo al igual que lo anteriormente comentado. Aunque estas cifras son representativas en cuanto al tipo de información, al diálogo y explicaciones en las etapas de ejecución en la RC, y que podría colegirse como una cualificación alta en la capacidad ciudadana como partícipe de rendición de cuentas, lo ideal sería que en dichos procesos se diera el diálogo entre los actores de la sociedad y del Estado, de manera directa, es decir, ir más allá de los informes regulares escritos, llenos de estadísticas, las más de las veces incomprensibles y tediosos.

Cumplimiento de lo establecido en la norma. Etapa de ejecución en cuanto a los Incentivos. En esta etapa, la articulación del marco normativo en materia de RC y su difusión, alcanza el $83 \%$; el reconocimiento del alcance y la utilidad de la RC el $90 \%$; el fortalecimiento del marco institucional y la formación de ciudadanos en peticiones de cuentas con el 87\%; y el apoyo a iniciativas ciudadanas de control social con el 67\%. Es reiterativo el horizonte estadístico, dígitos que muestran un avance significativo de la participación ciudadana en los procesos de RC. Las entidades en este caso dan cumplimiento a lo establecido en la norma, a los incentivos como articulación del marco normativo en materia de RC y su difusión, al reconocimiento del alcance y utilidad de la RC, al fortalecimiento del marco institucional, a la formación de ciudadanos en RC, y el apoyo a iniciativas ciudadanas de control social ${ }^{6}$.

A esta altura del análisis, cabe la siguiente pregunta: ¿La participación ciudadana en aumento, es el fruto de iniciativas estatales o de esfuerzos ciudadanos?

Si bien es cierto la participación ciudadana requiere como condición un conjunto de articulaciones como: instancias, actores entre intereses particulares y globales, entre participación ciudadana y representación política: es esencial entonces que estas articulaciones hayan surgido de las presiones ciudadanas y del interés estatal, lo que indicaría la existencia de una ciudadanía incentivada en el ejercicio de la RC participativa. De lo contrario la ciudadanía y las organizaciones sociales se cansarán de proponer y no ser escuchadas, y aún más, el conjunto de normatividad en aumento podría convertirse más en un desestimulo que en un incentivo a la participación ciudadana en los procesos de RC, y en el control social en general. Las entidades públicas deben aprovechar el hecho de que el ejercicio de RC, en el mayor porcentaje, se concentra en la ciudadanía en general, las organizaciones sociales y los funcionarios de las entidades públicas, lo que podría potenciar un

6. DOFA. Matriz de impacto. 
aumento en la promoción del control social, el incremento de la capacidad ciudadana y la responsabilidad ética de los funcionarios públicos.?

Etapa de evaluación de la Rendición de cuentas. Una mirada al documento CONPES 3654 permite identificar que uno de los lineamientos de la evaluación debe ser un proceso de aprendizaje continuo, que permita retroalimentar el diseño y la ejecución de las políticas y programas con base en el análisis y la medición de los resultados de la gestión. Es menester que esta retroalimentación tenga mecanismos de difusión que proporcionen a las entidades gubernamentales incentivos que estimulen el constante mejoramiento de su gestión, y a la ciudadanía con elementos que permitan ejercer un activo control social.

De igual manera, la ley 617 de 2000 estableció que el Departamento Nacional de Planeación debe realizar una evaluación de gestión de todas las entidades territoriales, incluidos sus organismos de control, y divulgar sus resultados por lo menos una vez al año en medios de amplia circulación nacional, con el objeto de apoyar el control social de la gestión pública territorial. Una vez verificado el espíritu de la norma y del documento CONPES, el análisis estadístico al interior de la etapa de la evaluación de la RC, muestra resultados significativos en cuanto a que: la realización de informes y actas alcanzan el $96 \%$, mientras que la publicación, divulgación de los informes y actas de la RC, y los resultados de la RC incorporados a los planes y proyectos, logran el $90 \%$. Se observa una aceptable realización en el proceso de RC en la etapa de evaluación.

Al ser evaluado el proceso de RC, frente a un discurso articulado, responsable e idóneo de los panelistas, ponentes y responsables de la entidad, ello permite percibir cambios en la gestión pública, transparencia administrativa y falencias en las políticas públicas, lo que provoca en la ciudadanía confianza hacia la entidad y fortalece el sentido de pertenencia frente a la gestión pública. Esto es indispensable para el acercamiento entre la ciudadanía y el Estado ${ }^{8}$.

Contrario a lo anterior, los funcionarios públicos y las organizaciones sociales manifestaron en el taller D.O.F.A. ${ }^{9}$ que los lineamientos de planificación no tienen en cuenta a las realidades territoriales, asunto que se contradice con lo antedicho en el análisis estadístico. De este panorama se puede inferir que en la gestión estatal podría existir la "cultura del secreto", es decir, un conjunto de actitudes y comportamientos de servidores públicos que consideran la información, las estadísticas, los informes de gestión y de RC, etc., como una propiedad estatal o de su patrimonio personal. Esto va en contravía de la obligación de rendir cuentas y asumir responsabilidades ante los ciudadanos por parte de los servidores públicos, es decir, de forjar transparencia y por consiguiente condiciones de confianza entre los entes públicos y la ciudadanía en su conjunto.

Organizaciones Sociales Constituidas. De los entes territoriales consultados a nivel nacional, se constató que tan solo la alcaldía de Pereira, para el año 2009, informó sobre la constitución de nuevas organizaciones sociales, en este caso, quince (15) veedurías ciudadanas fueron constituidas como Red. Estos resultados están en concordancia con los arrojados por el estudio de transparencia por Colombia 2008-2009. ${ }^{10}$ En lo que respecta a las entidades públicas

\footnotetext{
7 DOFA. Matriz de impacto.

8. DOFA. Matriz de impacto.

9. DOFA. Matriz de funcionarios públicos

10. Transparencia por Colombia. Índice de transparencia municipal, Resultados 2008-2009. Bogotá noviembre 25 de 2010. Pág. 15
} 
del orden nacional, tan solo un organismo de control, la Defensoría del Pueblo, informó para el mismo periodo, sobre el asesoramiento y capacitación a 48 organizaciones sociales.

\section{PASOS DE LA RENDICION DE CUENTAS SEGÚN GUÍA DAFP}

\begin{tabular}{|c|c|}
\hline PREPARACIÓN DE LA RENDICIÓN DE CUENTAS & COMENTARIOS A LOS PROCESOS \\
\hline \multicolumn{2}{|l|}{ Alistamiento Institucional } \\
\hline $\begin{array}{l}\text { Se cuenta en la entidad con un Grupo de Apoyo inte- } \\
\text { grado por un representante de cada área de la entidad } \\
\text { para la consolidación de la información que se entrega } \\
\text { en la RC }\end{array}$ & $\begin{array}{l}\text { En los documentos objeto de revisión se estableció, } \\
\text { en la gran mayoría, que se cumple con este ítem. } \\
\text { Este aspecto lo desconoce la ciudadanía y se mues- } \\
\text { tra como una debilidad. }\end{array}$ \\
\hline \multicolumn{2}{|l|}{ Identificación de Interlocutores } \\
\hline $\begin{array}{l}\text { La entidad cuenta con una base de datos de las orga- } \\
\text { nizaciones de la sociedad civil (asociaciones o comités } \\
\text { de usuarios, consejos regionales, gremios, veedurías, } \\
\text { universidades, medios de comunicación, asociaciones } \\
\text { de profesionales, etc.) beneficiarias de sus servicios }\end{array}$ & $\begin{array}{l}\text { En los documentos aportados se cumple con las ba- } \\
\text { ses de datos. La pregunta es: ¿Es la base de datos } \\
\text { que realmente integra a los interesados en la ges- } \\
\text { tión de lo público? }\end{array}$ \\
\hline $\begin{array}{l}\text { Registro de invitación de los usuarios a la RC para que } \\
\text { actúen como interlocutores. }\end{array}$ & $\begin{array}{l}\text { En los informes se cumple, pero concordante con lo } \\
\text { anterior, la pregunta es: ¿A quiénes invitan? }\end{array}$ \\
\hline \multicolumn{2}{|l|}{ Divulgación y capacitación } \\
\hline $\begin{array}{l}\text { Se cuenta con programas de capacitación y sensibili- } \\
\text { zación dirigidos a funcionarios, usuarios y/o organiza- } \\
\text { ciones de usuarios }\end{array}$ & $\begin{array}{l}\text { Sí se cuenta con programas de divulgación y capa- } \\
\text { citación. }\end{array}$ \\
\hline Se cuenta con espacios radiales y/ televisivos & Sí se cuenta efectivamente con estos espacios \\
\hline $\begin{array}{l}\text { Se realizan encuentros preparatorios de la audiencia } \\
\text { entre la entidad y las organizaciones sociales }\end{array}$ & $\begin{array}{l}\text { Los informes evidencian que se cumple, sin em- } \\
\text { bargo, la pregunta es: ¿Quiénes son los invitados a } \\
\text { dicho ejercicio preparatorio? }\end{array}$ \\
\hline \multicolumn{2}{|l|}{ Organización Logística } \\
\hline $\begin{array}{l}\text { Se tiene previsto un lugar para la realización de la Ren- } \\
\text { dición de Cuentas }\end{array}$ & Los informes señalan que sí lo cumplen. \\
\hline $\begin{array}{l}\text { Se tiene establecida una fecha para la realización de } \\
\text { la RC }\end{array}$ & Los informes señalan que sí lo cumplen. \\
\hline Se tiene establecido el tiempo de duración & Los informes señalan que sí lo cumplen. \\
\hline $\begin{array}{l}\text { Se cuenta con los suministros necesarios para la reali- } \\
\text { zación de la RC }\end{array}$ & Los informes señalan que sí lo cumplen. \\
\hline \multicolumn{2}{|l|}{ Reglamento de la audiencia de RC } \\
\hline Se cuenta con una agenda para su desarrollo & Los informes señalan que sí lo cumplen. \\
\hline Se tiene previsto el tiempo de intervenciones & Los informes señalan que sí lo cumplen. \\
\hline
\end{tabular}




\begin{tabular}{|l|l|}
\hline $\begin{array}{l}\text { Se cuenta con el proceso de inscripción y radicación } \\
\text { de propuestas }\end{array}$ & Los informes señalan que sí lo cumplen. \\
\hline $\begin{array}{l}\text { Existencia de formato para la inscripción de propues- } \\
\text { tas }\end{array}$ & Los informes señalan que sí lo cumplen. \\
\hline $\begin{array}{l}\text { Se cuenta con el proceso de inscripción de asistentes y } \\
\text { participantes que realizan preguntas en la RC }\end{array}$ & Los informes señalan que sí lo cumplen. \\
\hline $\begin{array}{l}\text { Se realiza análisis y clasificación de las propuestas y/o } \\
\text { evaluaciones recibidas }\end{array}$ & $\begin{array}{l}\text { Los informes señalan que sí lo cumplen. La pregun- } \\
\text { ta es: ¿Cuáles y con qué criterios se realiza el análi- } \\
\text { sis y clasificación de las propuestas? }\end{array}$ \\
\hline
\end{tabular}

Fuente: Equipo investigador.

\section{CRITERIOS REFERENTES A LA RENDICIÓN DE CUENTAS SEGÚN LA GUÍA DEL DAFP}

\begin{tabular}{|c|c|}
\hline CONTENIDOS & COMENTARIOS A LOS PROCESOS \\
\hline $\begin{array}{l}\text { Presentación de la RC financiera frente al presupuesto } \\
\text { asignado con un aparte especial referente a la totali- } \\
\text { dad de la contratación, inclusive de personal }\end{array}$ & $\begin{array}{l}\text { Los informes dicen que sí lo cumplen. La pregunta } \\
\text { sería: ¿Se informa en su totalidad de los aspectos } \\
\text { objeto de rendición? }\end{array}$ \\
\hline \multicolumn{2}{|c|}{\begin{tabular}{|l|l|} 
Presentación de la Rendición de Cuentas de Gestión & \\
\end{tabular}} \\
\hline Explicación Objeto Social de la entidad & Los informes señalan que sí lo cumplen. \\
\hline $\begin{array}{l}\text { Presentación de metas e indicadores de resultados } \\
\text { (Cantidad, costos, calidad y oportunidad) }\end{array}$ & $\begin{array}{l}\text { Los informes señalan que sí lo cumplen. La pregun- } \\
\text { ta es: ¿Presentan la totalidad de los indicadores de } \\
\text { gestión? }\end{array}$ \\
\hline $\begin{array}{l}\text { Presentación del Plan y presupuesto para la siguiente } \\
\text { vigencia }\end{array}$ & Los informes señalan que sí lo cumplen. \\
\hline \multicolumn{2}{|l|}{ Partes de la Rendición de Cuentas } \\
\hline $\begin{array}{l}\text { Presentación del informe de Rendición de Cuentas por } \\
\text { la entidad y el plan y presupuesto para la siguiente vi- } \\
\text { gencia }\end{array}$ & $\begin{array}{l}\text { Los informes señalan que sí lo cumplen. Este cri- } \\
\text { terio debe ser fundamental para incentivar a los } \\
\text { funcionarios, una vez sustente la gestión anterior. }\end{array}$ \\
\hline $\begin{array}{l}\text { Presentación de las evaluaciones o propuestas de } \\
\text { acciones, realizadas por las organizaciones de la so- } \\
\text { ciedad civil previamente inscritas y con documentos } \\
\text { radicados }\end{array}$ & $\begin{array}{l}\text { Los informes señalan que sí lo cumplen. Pero no } \\
\text { hay forma de validar si se incorporan a los procesos } \\
\text { de planeación posterior. Requiere de monitoreo y } \\
\text { seguimiento por parte de las organizaciones socia- } \\
\text { les y organismos de control. }\end{array}$ \\
\hline Intervenciones en general y aclaraciones & $\begin{array}{l}\text { Los informes señalan que sí lo cumplen, la pregun- } \\
\text { ta es: ¿Cuáles son los tipos de intervenciones que } \\
\text { se hacen, y si todas ellas están más encaminadas a } \\
\text { interrogar sobre la efectividad y eficacia de la ges- } \\
\text { tión de lo público? }\end{array}$ \\
\hline
\end{tabular}

Fuente: Equipo investigador 


\section{COMPONENTES FUNDAMENTALES DE LA RENDICIÓN DE CUENTAS SEGÚN DOCUMENTO CONPES 3654 DE 2010}

\begin{tabular}{|c|c|c|}
\hline & & COMENTARIOS A LOS PROCESOS \\
\hline \multirow{5}{*}{$\begin{array}{l}\text { TIPO DE } \\
\text { INFORMACIÓN }\end{array}$} & Comprensible & \multirow{5}{*}{$\begin{array}{l}\text { Si bien es cierto que en los informes se cumple con la información } \\
\text { y sus características establecidas, también lo es que dicha informa- } \\
\text { ción es preparada bajo la discrecionalidad de los funcionarios públi- } \\
\text { cos responsables de dicho proceso, lo que implica que los procesos } \\
\text { de depuración y entrega final al ciudadano, que ejerce el control } \\
\text { social, en algunos momentos se puedan distorsionar y ocultar cier- } \\
\text { tos datos para asumir posiciones frente a la gestión de lo público. } \\
\text { Se coincide con el documento CONPES en que uno de los ejes bási- } \\
\text { cos que limitan una apropiada RC, son las restricciones que sufre la } \\
\text { información cuando llega al ciudadano. }\end{array}$} \\
\hline & Actualizada & \\
\hline & Oportuna & \\
\hline & Disponible & \\
\hline & Completa & \\
\hline \multirow{4}{*}{$\begin{array}{l}\text { DIÁLOGO Y } \\
\text { EXPLICACIONES }\end{array}$} & $\begin{array}{l}\text { Comprensión en el } \\
\text { lenguaje y exposición }\end{array}$ & \multirow{4}{*}{$\begin{array}{l}\text { Según los documentos valorados, el momento del diálogo y ex- } \\
\text { plicaciones en la RC, se cumplen en cada uno de los aspectos } \\
\text { objeto de verificación; sin embargo se pudo establecer en los } \\
\text { talleres DOFA, que se presenta un escaso y limitado diálogo con } \\
\text { los asistentes a dicha rendición, espacio este fundamental para } \\
\text { retroalimentar aspectos susceptibles de ser mejorados en la } \\
\text { gestión de lo público. Esta aseveración coincide con los proble- } \\
\text { mas y limitaciones que plantea el documento CONPES } 3654 \text { de } \\
2010, \text { relacionados con el limitado diálogo que se presenta en } \\
\text { esta ámbito de la RC. }\end{array}$} \\
\hline & $\begin{array}{l}\text { Explicación de temas } \\
\text { relevantes para los fi- } \\
\text { nes de la RC }\end{array}$ & \\
\hline & $\begin{array}{l}\text { Diálogos de doble vía } \\
\text { que retroalimentan la } \\
\text { gestión pública }\end{array}$ & \\
\hline & $\begin{array}{l}\text { Convocatorias amplias } \\
\text { y frecuentes }\end{array}$ & \\
\hline \multirow{5}{*}{$\begin{array}{l}\text { LOS } \\
\text { INCENTIVOS }\end{array}$} & $\begin{array}{l}\text { Articulación del marco } \\
\text { normativo en materia } \\
\text { de RC y su difusión }\end{array}$ & \multirow{5}{*}{$\begin{array}{l}\text { Los incentivos como eje fundamental de la RC, en la perspectiva } \\
\text { de sancionar o motivar la labor realizada por los funcionarios } \\
\text { del gobierno de turno, se cumple según los informes de ges- } \\
\text { tión entregados y valorados en el presente estudio. Sin embar- } \\
\text { go, esta situación de incentivar positiva o negativamente a los } \\
\text { ciudadanos y servidores públicos, ha perdido interés en unos y } \\
\text { otros, expresado en la poca confianza que el ciudadano depo- } \\
\text { sita en las instituciones de la administración pública, así como } \\
\text { por la escasa motivación del funcionario, convirtiéndose en una } \\
\text { señal presumible de la debilidad del proceso de la RC. Esta argu- } \\
\text { mentación coincide con las debilidades establecidas en el taller } \\
\text { DOFA por parte de los ciudadanos, y con los planteamientos se- } \\
\text { ñalados en el mencionado documento CONPES. }\end{array}$} \\
\hline & $\begin{array}{l}\text { El reconocimiento del } \\
\text { alcance y la utilidad de } \\
\text { la } R C\end{array}$ & \\
\hline & $\begin{array}{l}\text { El fortalecimiento del } \\
\text { marco institucional }\end{array}$ & \\
\hline & $\begin{array}{l}\text { La formación de ciu- } \\
\text { dadanos en peticiones } \\
\text { de cuentas }\end{array}$ & \\
\hline & $\begin{array}{l}\text { El apoyo a iniciativas } \\
\text { ciudadanas de control } \\
\text { social }\end{array}$ & \\
\hline
\end{tabular}

Fuente: Equipo investigador

\section{ANÁLISIS DOFA DE LA RENDICIÓN DE CUENTAS A LA CIUDADANÍA DE LAS ENTIDADES NACIONALES}

\section{ANÁLISIS DE VULNERABILIDAD}

En el análisis de vulnerabilidad de la RC se tendrán presentes las siguientes pautas en el proceso de valoración: 
- Un criterio que sea de alto impacto es aquel que puede poner en riesgo de fracaso inminente (en el caso de debilidades y amenazas) el proceso de RC en las entidades públicas del orden nacional. Las causas pueden implicar altos niveles de corrupción, desinformación a la ciudadanía, no cumplimiento de la norma, etc. Cuando se trata de aspectos relacionados con fortalezas y oportunidades, la evaluación de alto impacto corresponde a eventos que, de presentarse, pueden tener efectos muy positivos, tales como puedan ser los casos de altos niveles de participación ciudadana, de transparencia en la gestión pública, mejoramiento en los procesos de información, mayor número de eventos de RC a la ciudadanía, entre otros, que pueden motivar y promover a procesos exitosos en la RC.

- Para el caso de la evaluación de bajo impacto, se consideran aspectos que pueden afectar negativa o positivamente la ejecución de los procesos de RC a niveles moderados, y que si la entidad pública posee los recursos humanos, técnicos, financieros, normativos, etc., los puede resolver en el caso de las debilidades y amenazas.

- En el caso de las fortalezas y oportunidades, son eventos que le pueden dar fortaleza a los procesos de RC e incluso para que éstos culminen en forma exitosa. Generalmente los aspectos de alto y medio impacto en el proceso de RC corresponden a las potencialidades que tienen las entidades públicas, para el logro exitoso de la RC en Colombia.

\section{MATRIZ DOFA DE IMPACTO}

\begin{tabular}{|c|c|c|c|}
\hline DEBILIDADES & ALTO & MEDIO & BAJO \\
\hline $\begin{array}{l}\text { 1. La comunidad y la ciudadanía en general presentan falencias en lo concernien- } \\
\text { te al conocimiento: de las normas que deben cumplirse, las entidades públicas, } \\
\text { los órganos de control, los conductos regulares, los instructivos o manuales de } \\
\text { procedimiento, dónde acudir para presentar denuncias, quejas, reclamos, su- } \\
\text { gerencias y acciones populares, como tampoco hacer veedurías ciudadanas y } \\
\text { RC. }\end{array}$ & DS & & \\
\hline $\begin{array}{l}\text { 2. Se evidencia poca voluntad política de parte de las instituciones para abrir es- } \\
\text { pacios a los procesos ciudadanos del control social y, por ende, a la coopera- } \\
\text { ción entre la ciudadanía y las entidades públicas, puesto que asumen que los } \\
\text { ciudadanos están poco enterados de la competencia y operatividad del Estado, } \\
\text { echando en saco roto la conformación de organizaciones sociales. }\end{array}$ & DP & & \\
\hline $\begin{array}{l}\text { 3. El proceso de RC en ocasiones se convierte en un informe plano de la gestión } \\
\text { administrativa de las entidades públicas, los temas tratados en su mayoría se } \\
\text { circunscriben a los informes de gestión que en general no explicitan las de- } \\
\text { mandas y/o presiones de las organizaciones sociales sobre temáticas cruciales. } \\
\text { Se presentan informes a conveniencia de las entidades públicas aprovechando } \\
\text { que la ciudadanía, en algunos casos, no tiene capacidad de decisión, ni voz, ni } \\
\text { voto frente a los informes que se presentan en la RC. }\end{array}$ & DI & & \\
\hline $\begin{array}{l}\text { 4. En ocasiones la RC no es considerada como un proceso estratégico de cualifica- } \\
\text { ción en la gestión pública, sino como un compromiso de coyuntura, de acuerdo } \\
\text { a circunstancias políticas y administrativas, a pesar de la débil participación de } \\
\text { la comunidad y de los funcionarios públicos en los procesos de RC, y la mínima } \\
\text { apropiación de la comunidad en los temas relacionados con el control social. }\end{array}$ & DP & & \\
\hline
\end{tabular}


5. Se evidencia falta de continuidad en la asistencia a procesos de RC por parte de los actores sociales, y en los procesos de seguimiento a la rendición de cuentas, por cambios constantes de los funcionarios públicos, así como ausencia de esquemas efectivos de evaluación y difusión para ejercer el control social. Esto lo demuestra la inexistencia de protocolos, el hecho de que muchas entidades públicas no dan a conocer las fechas y lugares donde se van a realizar estos procesos, la descontextualización histórica y el manejo de generalidades de la RC.

6. Algunos servidores públicos asumen actitudes defensivas frente al ejercicio de las veedurías ciudadanas, y creen que la entrega de la información los perjudica, mientras otros la ven como un favor y no como un deber, y cuando hacen entrega de dicha información, en muchos casos, es desarticulada, irreal, manipulada y fragmentada para los procesos de RC, así sea de un mismo sector. Entregada la información en estas condiciones, entorpece el control estatal de la gestión pública, incrementa la desinformación al ciudadano respecto al tipo de RC que se está desarrollando, aumenta la duda sobre el nivel de transparencia, sumada la desconfianza frente a la misma. Situación que hace pensar, por un lado, que no existen sistemas de información que le permitan al ciudadano, y a la comunidad en general, confrontar la información suministrada por los funcionarios, toda vez que la comunidad no la solicita en detalle para ser analizada, y por el otro, dado su creciente desinterés frente a la misma.

7. Se mantiene la desconfianza de la ciudadanía ante las instituciones públicas en procesos en los que no se observan resultados concretos, puesto que no se tienen en cuenta procesos anteriores referentes a los temas que se desarrollan; por el contrario, se visibilizan los compromisos politiqueros para la inversión de los recursos públicos, asociados al quehacer de la política colombiana, sin respetar, ni acatar las normas, primando el interés personal sobre el general; de allí el interés por parte de los políticos locales por la rendición de cuentas, y no por los recursos públicos presupuestados de inversión social, para beneficiar a las comunidades más necesitadas en materia de educación y salud.

8. En el proceso de RC no se evidencia en mayor proporción el cumplimiento del sistema regulador jurídico, sobre todo en el proceso de contratación, dada la cultura para burlar la ley buscando beneficios personales, en ocasiones la ley es superficial y se realiza para acatar la norma y, en el mayor de los casos, se muestra solo el cumplimiento de metas, es decir, el panorama positivo de la entidad; ello se reduce entonces a legalismos, que no surten ningún efecto en la sociedad, incrementando el analfabetismo ciudadano en esta materia.

9. El proceso de RC en muchos casos carece de una metodología homogénea, por tanto no es de fácil comprensión ni didáctica, ni con lenguaje apropiado que permita ser aplicable y captado por todas las capas de la sociedad. No hay herramientas pedagógicas para hacer esta actividad más dinámica. La mecánica de la RC es repetitiva. Se utiliza un lenguaje que no es claro, es incoherente con la ciudadanía, lo que determina que la presentación y exposición de cifras exponga una cara cuantitativa y no cualitativa de los temas a tratar, motivo por el cual los procesos de convocatoria no son llamativos para la comunidad.

10. La RC a través de la implementación de mesas de trabajo, consejos comunitarios, interlocución a través de internet, folletos y carteleras institucionales, es demasiado deficitaria y como tal, las políticas de divulgación y promoción de RC desde estos medios, van en contra vía al interés de las políticas que propenden por tales eventos. Igualmente, aunque en menor proporción, medios tan importantes y de utilización masiva como la radio y la televisión, y las audiencias públicas, presentan bajos niveles en la divulgación de la RC.

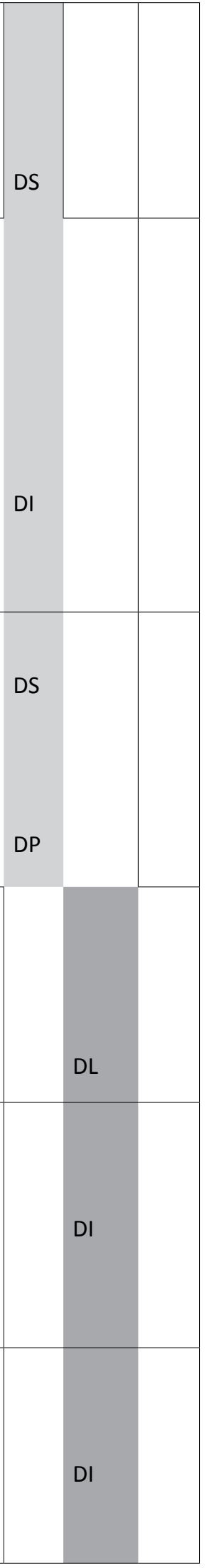




\begin{tabular}{|c|c|c|c|}
\hline $\begin{array}{l}\text { 11. Existe insuficiente conocimiento sobre los mecanismos para ejercer el control } \\
\text { social y la RC por parte de la ciudadanía y de los funcionarios públicos. Muchos } \\
\text { funcionarios de los organismos de control son reacios a promover las veedurías } \\
\text { ciudadanas, para así evitar el control a la gestión pública. }\end{array}$ & & DI & \\
\hline $\begin{array}{l}\text { 12. Existe escasa divulgación y socialización de los planes de desarrollo nacional } \\
\text { y territorial, y cuando se hacen, convocan a personas vinculadas a entidades } \\
\text { públicas con intereses políticos, lo que genera temor de los funcionarios pú- } \\
\text { blicos a mostrar los resultados, puesto que al parecer, están salpicados por la } \\
\text { corrupción en la desviación de los dineros públicos. Adicionalmente, la no con- } \\
\text { tinuidad de los funcionarios en las entidades públicas desvirtúa la RC, ya que no } \\
\text { hay quien responda con compromiso y responsabilidad honestamente, lo que } \\
\text { hace que el control social ejercido por ciudadanos, no tenga mucha incidencia } \\
\text { ni peso dentro de las entidades públicas. }\end{array}$ & & & DI \\
\hline $\begin{array}{l}\text { 13. La RC por sectores no se encuentra debidamente sistematizada en términos } \\
\text { de tiempo, veracidad y temática, no hay integralidad, pues no se evidencian } \\
\text { avances o dificultades en el orden territorial (Departamentos y Municipios), y, a } \\
\text { nivel nacional, además, con la creación y fusión de ministerios, el proceso de RC } \\
\text { se hace más dispendioso, dada la cantidad de información a organizar. }\end{array}$ & & & DI \\
\hline $\begin{array}{l}\text { 14. Al interior de las entidades públicas hay cierto desdén en la creación de una } \\
\text { cultura de lo público y, como tal, de la RC por parte de los funcionarios, con el } \\
\text { propósito de evitar sanciones. }\end{array}$ & & & DI \\
\hline $\begin{array}{l}\text { 15. Pocas entidades de control sobre lo público son tenidas en cuenta por los mis- } \\
\text { mos funcionarios de las entidades estatales en el proceso de RC, lo que podría } \\
\text { interpretarse como temor a la auditoría y fiscalización por los mismos. }\end{array}$ & & & DI \\
\hline FORTALEZAS & ALTO & MEDIO & BAJO \\
\hline $\begin{array}{l}\text { 1. Existencia de tecnología, información y comunicaciones (Tics) para promocionar } \\
\text { el proceso de RC, y promover el acercamiento del ciudadano a la administra- } \\
\text { ción pública, para legitimar la participación e intervención ciudadana, justificar } \\
\text { los programas de gobierno, los planes de desarrollo y el gasto de los recursos } \\
\text { públicos, visibilizar los procesos internos de la entidad, sobre todo los de calidad, } \\
\text { y facilitar el control a la ejecución de recursos públicos. }\end{array}$ & DI & & \\
\hline $\begin{array}{l}\text { 2. En los procesos de RC se evidenció que la mayoría de las entidades públicas cum- } \\
\text { plen con la etapa de preparación de la RC en el alistamiento institucional, identi- } \\
\text { ficación de interlocutores, divulgación y capacitación a funcionarios y ciudadanía, } \\
\text { organización logística y reglamento para las audiencias en la RC. }\end{array}$ & DI & & \\
\hline $\begin{array}{l}\text { 3. En los procesos de RC se comprobó que la mayoría de las entidades públicas } \\
\text { cumplen con la etapa de ejecución de la RC en contenidos, presentación y partes } \\
\text { de la RC; igualmente, en lo correspondiente al tipo de información, es decir, esta } \\
\text { es comprensible, actualizada, oportuna, disponible y completa. }\end{array}$ & DI & & \\
\hline $\begin{array}{l}\text { 4. Las entidades públicas, en los procesos de RC, dan cumplimiento a lo establecido } \\
\text { en la norma con respecto al diálogo y explicaciones, lo cual comprende proce- } \\
\text { dimientos organizacionales claros y favorables al diálogo, explicación de temas } \\
\text { relevantes para los fines de la RC, diálogos de doble vía que retroalimentan la } \\
\text { gestión pública y convocatorias amplias y frecuentes. }\end{array}$ & DI & & \\
\hline
\end{tabular}


5. En los procesos de RC se evidenció que la mayoría de las entidades públicas cumplen con la etapa de evaluación de la RC en donde: se realizan y publican informes, y se presentan actas de la RC, y los resultados de la RC se incorporan a los proyectos, además de permitir que se les haga seguimiento de su desempeño.

6. La RC les sirve a las comunidades para profundizar en el análisis sobre los resultados de la gestión pública, allí se desarrollan procesos de acercamiento entre las entidades y los ciudadanos, se crea una sensibilización en los ciudadanos sobre la forma como se invierten los recursos, y aumenta la conciencia ciudadana sobre la necesidad de exigir la rendición de cuentas a las entidades públicas.

7. Existen actas formales de RC, cuadernos documentales, sistematización de datos históricos y un marco jurídico, lo que le permite a la comunidad no solo conocer las cuentas, las estadísticas, hacer un análisis efectivo del tiempo y de la utilización adecuada de los recursos obtenidos para el desarrollo del país, sino la participación de todos los actores sociales en el proceso de RC.

8. Las entidades públicas en los procesos de RC dan cumplimiento a lo establecido en la norma en lo tocante a los incentivos, como articulación del marco normativo en materia de RC y su difusión, reconocimiento del alcance y utilidad de la RC, el fortalecimiento del marco institucional, la formación de ciudadanos en RC y el apoyo a iniciativas ciudadanas de control social.

9. Manifiesto interés de algunas entidades territoriales y de los órganos de control en la promoción del control social a la gestión pública, como ejercicio de avalar la transparencia en la gestión pública en términos de procedimientos, resultados, destino eficiente de los recursos, y dar a conocer los proyectos y programas sociales a nivel nacional y territorial.

10. Las entidades públicas para promocionar la RC, utilizan en mayor medida las páginas web institucionales, los boletines de prensa y el Boletín del Consumidor.

11. En algunas entidades públicas se evidencia organización, capacidad de convocatoria, pertinencia e incremento en recursos físicos, humanos y de capital en los procesos de RC.

12. Existe aprovechamiento por parte de algunas entidades públicas de los procesos de rendición de cuentas para implementar el sistema de gestión de calidad, y el modelo de control interno.

13. Los mecanismos de participación ciudadana se involucran y desarrollan en las funciones de las veedurías ciudadanas para ejercer el control social.

\section{AMENAZAS}

1. Es frecuente la presentación de informes de gestión muy generales y que no $D$ evidencian lo concreto de una RC, indicativo del poco control político por parte de las entidades de control y de la ciudadanía en general, además existe temor por parte de la ciudadanía en los procesos de RC a hacer denuncias sobre corrupción, mala gestión, etc., so pena de perder subsidios o recibir represalias.

2. La mayoría de los ciudadanos pierden el interés por las actividades de control social, debido a la corrupción de la clase política que se perpetúa en la impunidad, a la apropiación de recursos públicos y abuso de poder de los funcionarios públicos. Ante este hecho, la ciudadanía no tiene como comprobar y verificar los informes de cuentas y estadísticas que presentan los funcionarios en la RC. 
3. Subsiste la manipulación de las bases de datos del sistema de selección de beneficiarios y familias en acción, para beneficios políticos personales de los funcionarios, lo que hace que la RC no sea transparente, dado que en las mismas audiencias públicas, los funcionarios públicos se comprometen a solucionar los problemas de la comunidad y, en la práctica, nunca son solucionados; por tanto, el nivel de las respuestas es inconcluso y, por lo mismo, de nulo impacto.

4. Falta de recursos de la ciudadanía para ejercer el control social y participar en la rendición de cuentas, aunado a un alto nivel de indiferencia y analfabetismo de la comunidad en el proceso de RC.

5. Algunas entidades públicas se muestran reacias a la participación ciudadana y a la RC, dado que la ciudadanía encuentra falencias en la responsabilidad y moralidad en los servidores públicos, pues es débil el compromiso de asumir los códigos de ética establecidos para el logro eficiente y eficaz en la promoción del control social.

6. Existe suficiente normatividad para la RC, pero gran parte de la comunidad no la conoce y muchos funcionarios públicos no la promueven.

7. En los procesos de RC priman los intereses de grupos políticos de acuerdo a coyunturas de orden público y político, de los llamados grupos de presión, lo que posibilita la manipulación de la información según intereses políticos personales.

\section{OPORTUNIDADES}

1. Existen cartillas pedagógicas elaboradas por el DAFP, por la Controlaría General de la República y demás órganos de control sobre los mecanismos de promoción del control social, dirigidas a la capacitación de los líderes comunales, organizaciones sociales, veedurías ciudadanas, funcionarios públicos, organismos no gubernamentales y ciudadanía en general, para aumentar los procesos de capacitación en control social y política pública.

2. Al ser evaluado el proceso de Rendición De Cuentas, frente a un discurso articulado, responsable e idóneo de los panelistas, ponentes y responsables de la entidad, ello permite percibir cambios en la gestión pública, transparencia administrativa y falencias en las políticas públicas, lo que provoca en la ciudadanía confianza hacia la entidad y fortalece el sentido de pertenencia frente a la gestión pública. Esto es indispensable para el acercamiento entre la ciudadanía y el Estado.

3. Las veedurías ciudadanas hacen control social sobre planes, programas y proyectos institucionales en los procesos de RC, por tanto éstos representan un insumo para el sector privado, que requiere contar con climas seguros para la inversión, rechazan la corrupción y piden implementar instrumentos de control más efectivos.

4. Las entidades públicas deben aprovechar el hecho de que el ejercicio de RC DS en el mayor porcentaje, se concentra en la ciudadanía en general, las organizaciones sociales y los funcionarios de las entidades públicas, lo que podría potenciar un aumento en la promoción, no sólo del control social, sino en el incremento de la capacidad ciudadana y la responsabilidad ética de los funcionarios públicos. 
5. La RC permite a las entidades públicas, dar a conocer a las comunidades y a las organizaciones sociales, el desarrollo de sus actividades y percibir la sensación que se genera en los ciudadanos. Es así como en la interacción generada entre funcionarios públicos y comunidad, los primeros pueden priorizar las temáticas propuestas surgidas desde las organizaciones sociales y la ciudadanía en general, y las segundas, es decir las organizaciones sociales, van logrando abrir espacios que fortalecen su representatividad ante la misma sociedad y los estamentos públicos.

6. Tanto los funcionarios públicos como la comunidad y las organizaciones sociales, convierten el proceso de RC en mecanismo de control para fortalecer el Estado Social de Derecho. El ciudadano como ser vital de lo público y conocedor de sus derechos, tiene facultades para reclamar los mismos, y los funcionarios públicos conocedores de sus deberes, permiten a los ciudadanos acercarse a las instituciones y demandar por sus derechos sobre la utilización de los recursos provenientes de sus impuestos.

7. Con la oferta de medios de difusión e implementación de sistemas de información multisectoriales y las TICs, se genera la rápida difusión de la información dado su aumento en el proceso de divulgación en páginas web, radio, prensa, televisión, (canal institucional) para que las entidades públicas se conecten con las organizaciones sociales y la comunidad, y se enteren del día, hora y lugar donde se llevará a cabo la RC, como un evento que permite conocer la gestión pública, al convertirlo en el espacio para que las comunidades y las personas puedan participar, opinar y ser tenidas en cuenta.

8. En la estrategia de audiencias públicas que desarrollan entidades como la Contraloría General de la Nación, la Fiscalía, la Procuraduría, y el programa presidencial de lucha contra la corrupción, a través de la cual se ponen de manifiesto los hechos de corrupción y se imponen sanciones correctivas.

9. Como la RC es un espacio adecuado para denunciar la corrupción por el mal uso de los recursos públicos, las organizaciones sociales las aprovechan para hacer peticiones, quejas, reclamos y sugerencias de todos los órdenes, sustentadas con la abundante normativa que existe en el país para tal fin.

10. Aprovechar los consejos comunitarios para demandar procesos de RC a la ciudadanía y potenciar el documento CONPES 3654, para consolidar la rendición de cuentas como un proceso permanente entre la rama ejecutiva y los ciudadanos.

11. Los procesos de rendición generan espacios a las entidades públicas para: Lograr la Certificación en Gestión Ambiental ISO 14001, Acreditación Internacional y Nacional por parte del ICONTEC, Certificación ISO 9001, así como los altos índices de satisfacción del usuario.

12. La actitud responsable de algunos funcionarios en la RC, permite que la información presentada a la ciudadanía sea clara y transparente. Espacios que permiten la discusión de necesidades de las entidades públicas y de las comunidades. 
El proceso de RC debe ser incluyente, en la medida en que se valore la real importancia de la participación ciudadana en los procesos de control a la gestión pública, y, a su vez, que la institucionalidad implemente los mecanismos y la normatividad existente, para que sus funcionarios ganen en calidad, en prestigio y obviamente en el desempeño de su gestión.

El concepto de inclusión se configura como el punto de partida para que actores tales como: ciudadanos, órganos de control, funcionarios y entidades públicas, contribuyan a la generación de una mayor participación ciudadana que genere cambios sustanciales en la actitud frente a lo público, en la crítica y autocrítica constructiva desde la ciudadanía hacia los funcionarios públicos, y viceversa, es decir, implementar una cultura de redes sociales que conduzca al logro de la eficacia y la eficiencia entre la sociedad civil, los órganos de control y las entidades públicas con sus funcionarios. En este orden de ideas, hay que señalar conceptos como la transparencia, la corrupción, la gobernabilidad, la visibilidad de la información y la cultura hacia la RC, pues son elementos claves que constituyen un todo y como tal deben ser considerados por los actores sociales y estatales, en los procesos de cualificación de la gestión pública y de la capacidad ciudadana. Aspectos como la información y la comunicación deben ser evaluados permanentemente, por ser insumos claves en los procesos de RC y puente entre las organizaciones sociales, entidades públicas y organismos de control. De allí que tales criterios deben ser claros, concretos, concisos, ya que son el puntal de la cultura de red y fuente de intervención institucional. Es entonces definitivo en el proceso de RC la convocatoria permanente a la ciudadanía, y sus organizaciones, en los procesos de formulación, preparación, ejecución y evaluación de planes, programas y proyectos de desarrollo, pues de esta manera se consolida la verdadera democracia participativa con transparencia, mínimos de corrupción, efectivo control político, y, ¿por qué no?, que la ciudadanía cuente con una gama de estrategias de crecimiento económico, político y social de las cuales siempre es partícipe directa.

\section{CONCLUSIONES}

La carta política de 1991 reconoce la soberanía del pueblo en un Estado Participativo, y la Ley 489 instaura que todas las entidades y organismos de la administración pública tienen la obligación de desarrollar su gestión acorde con los principios de democracia participativa, y democratización de la gestión pública. Para dar cumplimiento a lo anterior, la ley dice que las entidades públicas podrán realizar las acciones requeridas con el objeto de involucrar a los ciudadanos, y organizaciones de la sociedad civil, en la formulación, ejecución, control y evaluación de la gestión pública, dentro de lo cual tiene importancia la Rendición De Cuentas a la ciudadanía, acción incluida en la Política de Desarrollo Administrativo establecida en la Ley 489 de 1998, y el Decreto 3622 de 2005.

Se demostró que los medios de divulgación más utilizados por las entidades públicas son las páginas web institucionales y el Boletín del Consumidor, los cuales alcanzan el 100\% de utilización, seguidos por otros medios de divulgación, con el 50\%, los boletines de prensa, con el 43\%, la televisión institucional el 23\%, las audiencias públicas, el 17\%, y la radio, el 13\%, como las más destacados. Para esas audiencias públicas invitaron a 15.221 personas, entre organizaciones de la sociedad civil identificadas como de representación territorial, quienes hicieron sesenta y tres (63) intervenciones.

Esta referencia estadística evidenció un alto nivel de oferta en la utilización de los medios de información para la RC a la ciudadanía, de por sí sugiere que la ciudadanía cada vez está más 
informada al tener acceso directo a la información, debido al avance de la ciencia, la tecnología, la informática y las comunicaciones oportunas y de calidad, que favorecen la decisión ciudadana en participar en procesos como la RC.

Análisis que se ratifica en el ejercicio pedagógico realizado en el taller focal con metodología DOFA, el cual arrojó las siguientes aseveraciones:

- Existencia de tecnología, información y comunicaciones (Tics) para promocionar el proceso de RC, por medio del cual se promueve el acercamiento del ciudadano a la administración pública, para legitimar la participación e intervención ciudadanas, justificar los programas de gobierno, los planes de desarrollo y el gasto de los recursos públicos, visibilizar los procesos internos de la entidad, sobre todo los de calidad, y facilitar el control a la ejecución de recursos públicos.

- Existen cartillas pedagógicas elaboradas por el DAFP, por la Controlaría General de la República y demás órganos de control sobre los mecanismos de promoción del control social, dirigidas a la capacitación de los líderes comunales, organizaciones sociales, veedurías ciudadanas, funcionarios públicos, organismos no gubernamentales y ciudadanía en general, para aumentar los procesos de capacitación en control social y política pública.

En el proceso de participación del ciudadano capacitado en la RC se demostró que la acción de capacitación es la más representativa por parte de las Entidades de la Administración Pública del orden nacional, reconociendo que dicho acto formativo, no garantiza que efectivamente se produzca la RC por parte de la ciudadanía. La formación, si bien es cierto, es una estrategia importante para construir cultura ciudadana de la participación, también lo es que ésta debe estar acompañada de otro tipo de mecanismos y escenarios que permitan al ciudadano la apropiación cultural de dicho deber y derecho, de controlar socialmente la gestión de lo público. Ahora bien, si nos atenemos a la información referente a la acción promocional y de capacitación a los ciudadanos, como punta de lanza para su participación en procesos como el de RC, se puede constatar que en el tipo de acción promovida por las entidades públicas, organismos de control y organizaciones no gubernamentales, tanto los organismos de control con el 38.5\%, y las ONG's con el 53.8\%, encausan su actividad promocional en la asesoría, lo cual se explica probablemente por su carácter institucional de apoyo a procesos de consolidación a las organizaciones sociales que vienen ejerciendo el derecho al control social. La capacitación ocupa un segundo lugar, coincidiendo con la práctica de las entidades de la administración pública del orden nacional.

Así mismo, contrastando la información documental plasmada en la ficha para la revisión documental-cualificación del proceso de RC, y el taller DOFA, se detectaron las siguientes falencias en cuanto a los conceptos de información y participación que van en contravía respecto a los efectos positivos en la ciudadanía, del proceso de RC:

- Poca voluntad política de parte de las instituciones públicas para abrir espacios a la participación ciudadana y a la cooperación entre ésta y las entidades públicas, subestimando el conocimiento que la ciudadanía y sus organizaciones tienen sobre la competencia y operatividad del Estado. Falta de recursos de la ciudadanía para participar en la RC, aunado a un alto nivel de indiferencia y analfabetismo de la comunidad en el proceso de RC. 
- Existe suficiente normatividad para la RC, pero gran parte de la comunidad no la conoce y muchos funcionarios públicos no la promueven. Además, la comunidad y la ciudadanía en general presentan falencias en lo concerniente al conocimiento: de las normas que deben cumplirse, las entidades públicas, los órganos de control, los conductos regulares, los instructivos o manuales de procedimiento, dónde acudir para presentar denuncias, quejas, reclamos, sugerencias y acciones populares, como tampoco saben hacer veedurías ciudadanas y exigir RC.

- Algunos servidores públicos asumen actitudes defensivas frente al ejercicio de las veedurías ciudadanas, y creen que la entrega de la información los perjudica, mientras otros la ven como un favor y no como un deber, y cuando hacen entrega de la información, en muchos casos es desarticulada, manipulada y fragmentada para los procesos de RC, así sea de un mismo sector. Entregada la información en estas condiciones, entorpece el control estatal de la gestión pública, incrementa la desinformación al ciudadano respecto al tipo de $\mathrm{RC}$ que se está desarrollando, aumenta la duda sobre el nivel de transparencia, sumada la desconfianza frente a la misma. No existen sistemas de información que le permitan al ciudadano y a la comunidad confrontar la información suministrada por los funcionarios, toda vez que la comunidad no la solicita en detalle para ser analizada, además de su desinterés frente a la misma.

- El proceso de RC en muchos casos carece de una metodología homogénea, de herramientas pedagógicas y utiliza un lenguaje hiperespecializado para la ciudadanía. En gran medida, no cumplen las expectativas de la ciudadanía y se circunscriben a los informes de gestión, que en general no explicitan las demandas y/o presiones de las organizaciones sociales sobre temáticas cruciales. Se presentan informes a conveniencia de las entidades públicas.

- La RC a través de la implementación de mesas de trabajo, consejos comunitarios, interlocución a través de internet, folletos y carteleras institucionales, es demasiado deficitaria, y, como tal, las políticas de divulgación y promoción de RC desde estos medios, van en contra vía del interés de las políticas que propenden por tales eventos. Igualmente, aunque en menor proporción, medios tan importantes y de utilización masiva como la radio, la televisión y las audiencias públicas, presentan bajos niveles en la divulgación de la RC.

- Existe escasa divulgación y socialización de los planes de desarrollo nacional y territorial, y cuando lo hacen, convocan a personas vinculadas a entidades públicas con intereses políticos, lo que va en contra de las políticas de anticorrupción y, en general, de la transparencia de la gestión pública. Es entonces en este contexto que la información está en concordancia con lo afirmado por la Convención Interamericana de Derechos Humanos, al referirse al acceso a la información pública: "comprende una obligación positiva en cabeza del Estado de brindar a los ciudadanos acceso a la información que está en su poder, y un derecho correlativo de las personas a acceder a información en poder del Estado..." -citado por Transparencia por Colombia (Informe anual 2009 Págs. 15-20) en el acápite acceso a la información pública en Colombia: ¿Un derecho vulnerado?

En lo concerniente a los efectos de la RC en la gestión pública, los resultados expresados en el documento DOFA son elocuentes, toda vez que explicitan lo siguiente:

- Se evidenció que la mayoría de las entidades públicas cumplen con la etapa de preparación del proceso en el alistamiento institucional, identificación de interlocutores, divulgación y capacitación a funcionarios y ciudadanía, organización logística y reglamento para las audiencias en la RC; y con etapa de ejecución respecto a contenidos, presentación y partes de la RC. Dan cumplimiento a la norma con respecto al diálogo y explicaciones, lo cual comprende procedimientos organizacionales y favorables al diálogo, explicación de temas 
relevantes para los fines de la $\mathrm{RC}$, diálogos de doble vía que retroalimentan las gestiones públicas y convocatorias amplias y frecuentes. Dan cumplimiento a lo establecido en la norma en lo que tiene que ver con los incentivos como articulación del marco normativo y su difusión, reconocimiento del alcance y utilidad, el fortalecimiento del marco institucional, la formación de ciudadanos y el apoyo a iniciativas ciudadanas de control social. Se evidencia organización, capacidad de convocatoria, pertinencia e incremento en recursos físicos, humanos y de capital en los procesos de RC. Cumplen con la etapa de evaluación de la RC en donde: se realizan y publican informes, se presentan actas y los resultados se incorporan a los proyectos, permitiendo que se le haga seguimiento a su desempeño.

- La RC le sirve a las comunidades para profundizar en el análisis sobre los resultados de la gestión pública, allí se desarrollan procesos de acercamiento entre las entidades y los ciudadanos, se crea una sensibilización sobre la forma como se invierten los recursos, y aumenta la conciencia ciudadana sobre la necesidad de exigir la RC por parte de las entidades públicas.

- Manifiesto interés de algunas entidades territoriales y de los órganos de control en la promoción del control social a la gestión pública, como ejercicio de avalar la transparencia en términos de procedimientos, resultados, destino eficiente de los recursos, y dar a conocer los proyectos y programas sociales a nivel nacional y territorial.

- Las veedurías ciudadanas hacen control social sobre planes, programas y proyectos institucionales en los procesos de RC, los cuales representan un gran insumo para el sector privado, que requiere contar con climas seguros para la inversión y, por tanto, rechazan la corrupción y llaman a implementar instrumentos de control más efectivos.

\section{BIBLIOGRAFÍA}

- Constitución Política de Colombia.

- Contraloría General de la República. Audiencias Públicas en la ruta de Rendición de Cuentas a la Ciudadanía de la Administración Pública Nacional. Bogotá, Mayo 2009, págs. 10-11

- CUNILL GRAU, Nuria. La rendición de cuentas y el control social. Una aproximación conceptual (Abril 2007).

- Decreto 01 de 1984. Código Contencioso Administrativo.

- Decreto 1151 de 2008.

- Documento CONPES 3654.

- Ley 136 de 1994.

- Ley 152 de 1994.

- Ley 489 del 1998.

- Ley 617 de 2000.

- Ley 715 de 2001.

- Ley 850 de 2003.

- Ley 850 del 2003.

- Ley 962 de 2005.

- Ministerio del Interior y de justicia.

- QUINTERO NEIRA, Jesús. El buen servidor público. Esap. Bogotá 2006 Pág 21.

- Resolución Orgánica No. 5544 de 2003.

- Sentencia C-292 de 203.

- Transparencia por Colombia. Índice de transparencia municipal, Resultados 2008-2009.

- Bogotá Noviembre 25 de 2010. Pág. 15. 